\title{
PENGEMBANGAN DIGITAL STORY TELLING UNTUK MENUMBUHKAN KEBIASAAN ANAK MINUM AIR
}

\author{
Iis Hidayati', Wahyu Sukartiningsih ${ }^{2}$, Umi Anugerah Izzati ${ }^{3}$ \\ Program Studi Pendidikan Dasar, Pascasarjana, Universitas Negeri Surabaya ${ }^{1,2,3}$. \\ Email:hidayatiiis573@gmail.com¹; wahyusukartiningsi@unesa.ic.id²; UmiAnugerah@unesa.ic.id ${ }^{3}$ \\ Hidayati, iis. Wahyu Sukartiningsih. Umi Anugerah Izzati. (2021). Pengembangan Digital Story Telling untuk \\ Menumbuhkan Kebiasaan Anak Minum Air. Jurnal Pelita PAUD, 6(1), 1-6. \\ doi: https://doi.org/10.33222/pelitapaud.v6i1.1345
}

Diterima:26-08-2021

Disetujui: 24-08-2021

Dipublikasikan: 21-12-2021

\begin{abstract}
Abstrak: Penelitian ini bertujuan untuk mendeskripsikan proses pengembangan digital story telling untuk menumbuhkan kebiasaan anak minumair; Menghasilkan produkpengembangan digital story telling untuk menumbuhkan kebiasaan anak minumair dan; Menghasilkan produk pengembangan digital story tellinguntuk menumbuhkan kebiasaan anak minumair. Berdasarkan hasil analisis data, dapat disimpulkan bahwa pengembagangan digital storytelling untuk menumbuhkan kebiasaan anak minum air meliputi tiga hal, yaitu Pengembangan digital storytelling untuk menumbuhkan kebiasaan anak usia minum air memenuhi kelayakan dengan hasil validasi dari tiga validator ahli yang meliputi materi isi dengan skor $75,71 \%$, materi teknik storytelling skor $82,14 \%$, materi desain pengembangan digital storytelling skor 72,85 $\%$ dengan kategori sangat berkualitas; Pengembangan digital storytelling untuk menumbuhkan kebiasaan anak minum air merupakan hasil pengembangan media pembelajaran yang dapat membantu daring online guru disaat pandemi untuk tetap dapat mengedukasi yang menarik minat anak dan meningkatkan motivasi wawasan anak dan orang tua akan pentingnya menumbuhkan kebiasaan minum air sejak dini dan; pengembangan digital storytelling untuk menumbuhkan kebiasaan anak minum air cukup praktis dan efektif diimplementasikan karena dikemas dalam bentuk kanal youtobe,sehingga mudah di akses dengan mudah saat ini.
\end{abstract}

Kata kunci: Digital, Story Telling, Menumbuhkan, Kebiasaan, Anak

Abstract: This study aims to: Describe the process of developing digital story telling to grow children's drinking habits; Produce digital story telling development products to foster children's drinking habits and; Produce digital story telling development products to foster children's drinking habits. Based on the results of data analysis, it can be concluded that the development of digital story telling to grow children's drinking water habits includes three things, namely The development of digital story telling to grow the habits of children drinking water meets eligibility with validation results from three expert validators covering content material with a score of $75.71 \%$, story telling technique materials score $82.14 \%$, digital story telling development design materials score $72.85 \%$ with a very high quality category; The development of digital story telling to grow children's drinking water habits is the result of developing learning media that can help online teachers during a pandemic to still be able to educate children that attract children's interests and increase the motivation of children's and parents' insight into the importance of growing the habit of drinking water from an early age and; the development of digital story telling to cultivate the habit of children drinking water is quite practical and effectively implemented because it is packaged in the form of a YouTube channel, so that it is easily accessible at this time.

Keywords: Digital, Story Telling, Growing, Habits, Children

(C) 2021 Iis Hidayati1 ${ }^{1}$, Wahyu Sukartiningsih ${ }^{2}$, Umi Anugerah Izzati ${ }^{3}$ Under the license CC BY-SA 4.0

http://jurnal.upmk.ac.id/index.php/pelitapaud 


\section{PENDAHULUAN}

Berdasarkan Peraturan Pemerintah Republik Indonesia nomor 19 tahun 2005 tentang Standar Nasional Pendidikan Anak Usia Dini adalah upaya pembinaan kemampuan perkembangan dan pertumbuhan anak yang akan dicapai berdasarkan kriteria seluruh aspek yang meliputi aspek nilai agama dan moral, fisik motorik, kognitif, bahasa, sosial emosional serta seni (Penmendikbud, 2014). Anak usia dini adalah anak yang berusia 0-8 tahun. Masa ini kehidupan anak disebut dengan istilah usia emas (golden age) yang merupakan "masa peka" dan hanya datang sekali. Anak membutuhkan kondisi yang sesuai dengan kebutuhannya sehingga pertumbuhan dan perkembangan anak dapat tercapai secara optimal(Permendikbud No. 137 Tahun 2014, n.d.). Dalam hal ini adalah kecukupan air minum anak perhari yang sangat penting menyangkut pertumbuhan fisik dan kognisi anak. Rata-rata anak usia dini khususnya di Taman Kanak-kanak memiliki kebiasaan yang kurang minat dalam mengkonsumsi air putih yang cukup sesuai kebutuhan anak setiap harinya. Mengingat anak-anak adalah periode penting yang menentukan seluruh perkembangan pertumbuhan hidupnya, untuk diketahui bahwa lebih dari $70 \%$ tubuh anak memerlukan cairan untuk mencapai tumbuh kembang yang optimal sehingga keseimbangan air perlu dipertahankan. Organ penting seperti otak, jantung, dan paru sebagian besar adalah air.(Dewi, 2020)

Penting sekali bagi tubuh anak termasuk kita orang dewasa untuk tetap tercukupi kebutuhan cairan, agar organ dalam tubuh dapat berfungsi secara optimal pula.Fakta yang terjadi anak lebih cenderung menyukai minuman yang berasa dan berwarna.

Menurut artikel Aqua Lestari sebuah survei menyatakan jika hanya $6,1 \%$ anak yang terbiasa minum air di pagi hari. Sementara 24,4\% anak lainnya, baru minum air ketika mereka makan dan $33,5 \%$ minum ketika sore hari(Wiranata, 2019). Hal ini menandakan bahwa masih banyak anak-anak yang kurang dibiasakan minum air sesuai kebutuhannya.

Air putih merupakan sumber terbaik untuk mencukupi kebutuhan cairan tubuh. Air paling alami tidak mengandung pewarna, pemanis dan perasa. Selama ini kita tak menyadari jika anakanak banyak yang kurang minat untuk terbiasa minum air putih. Sehingga sering terjadi kekurangan cairan yang berpengaruh pada pola kesehatan dan menggangu tumbuh kembang anak.Untuk kebutuhan air pada anak setiap hari tidak jauh berbeda dengan orang dewasa. Kebutuhan cairannya mencapai rata-rata anak yang telah berusia lebih dari satu tahun, maka sesuai dengan angka kecukupan gizi 2013 yang ditentukan Kementerian Kesehatan Republik Indonesia,yaitu: 1) Usia 1-3 tahun: membutuhkan cairan sebanyak 1150-1200 ml (4-5 gelas) per hari; 2) Usia 4-6 tahun:membutuhkan cairan sebanyak $1450-1500 \mathrm{ml}$ (6 gelas) perhari.

Anak perlu minum air lebih banyak, kekurangan minum air putih dapat menyebabkan dehidrasi yang akan memiliki dampak menurunkan kemampuan aktifitas fisik (Kleiner, 1999). Kekurangan air akan berdampak pada ketahanan fisik anak yang menurun, lebih mudah lelah, kelesuan dan penurunan fungsi kognitif otak anak (D'Anci, 2005). Dampak lain yang menganggu pada perkembangan anak adalah berkurangnya kemampuan konsentrasi anak atau kefokusan dengan menurunnya daya ingat (Benton dan Burgess, 2009).

Untuk itu menumbuhkan kebiasaan mengkonsumsi air putih pada anak sangat penting agar anak tidak terbiasa menyukai minuman bergula/berasa dan berkalori yang dapat meningkatkan resiko obesitas pada anak dan berakibat penyakit kronis dewasa kelak. Oleh sebab itu, minum air putih harus dibiasakan sejak usia dini. Perlunya membangun pemahaman konsep pada anak usia dini untuk menumbuhkan kebiasaan anak minum air. Diperlukan program dan metode pembelajaran yang mampu menarik minat, dan motifasi yang cukup mengedukasi anak sejak dini dan orang tua sebagai pendamping kehidupan sehari-hari anak dirumah.

Menurut (Piaget dan Kohlberg, 1969) dalam (Subadrah.M.N, Najeemah. M. Y, 2014), penggunaan metode story telling cocok untuk pengajaran dan pembelajaran Pendidikan pembiasan, terutama di kalangan anak-anak. Ini bertujuan untuk membentuk kebiasaan minum air putih pada anak yang berfondasi pada 3 hal penting: pentingnya minum air putih, untuk pertumbuhan fisik yang kuat, selain dari pentingnya konsumsi makanan bergizi, dan pentingnya bergerakaktif.

Karena keterbatasan penelitian, terutama dalam keadaan pandemi covid 19, penelitian pengembangan digital story telling untuk menumbuhkan kebiasaan anak minum air ini akan mengembangkan produk digital melalui multimedia sebagai media pembelajaran yang dapat digunakan guru untuk mengedukasi anak Taman Kanak-kanak dan orang tua dalam proses pembelajaran daring online masa pandemi covid 19.(Cahyati \& Kusumah, 2020),

Perkembangan dunia digital sangat berkembang pesat saat ini, agar tidak tertinggal oleh perkembangan zaman maka kita harus mampu 
mengikuti perkembangan tersebut. Sebuah pengembangan inovasi dalam dunia pendidikan sangatlah dibutuhkan terutama dalam memberikan media belajar online/daring saat pandemi covid 19(Sutarna et al., 2022), dalam hal ini inovasi media pengembangan digital story telling.Penggunaan media digital story telling diharapkan mampu memberikan edukasi siswa untuk menumbuhkan kebiasaan anak minum air dalam proses pembelajaran jarak jauh. Pengembangan digital story telling merupakan media pembelajaran multimedia yang digunakan guru untuk menyampaikan materi pembelajaran dalam bentuk story telling yang dituangkan dalam bentuk aplikasi digital yang dapat di share melalui channel you tube,supaya media tersebut dapat dilihat dan disimak secara daring oleh siswa dan orang tua kususnya dalam pendampingan proses pembelajaran anak usia dini.Penyajian media digital story telling meliputi materi isi,teknik story telling dan desain yang tertuang dalam sebuah tayangan edukasi vidio pembelajaran.

\section{METODE PENELITIAN}

penelitian ini menggunakan metode penelian dan pengembangan (Research and Development). Menurut (Sugiyono, 2017). "Metode penelitian dan pengembangan dapat diartikan sebagai cara ilmiah untuk meneliti, merancang, memproduksi dan menguji validitas produk yang telah dihasilkan". Memvalidasi produk, berarti produkitu telah ada, dan peneliti hanya menguji efektifitas produk atau validitas produk tersebut. Mengembangkan produk dalam arti dapat berupa memperbarui produk yang telah ada (sehingga lebih praktis, efektifdan efisian). Pengembangan digital storytelling yang dilakukan peneliti adalah pengembangan digital multimedia sebagai media belajar online anak usia dini.

Penelitian ini berlangsung di TK Aisyiah 07, Jl.Raya Kalibokor Surabaya.

Peneliti menetapkan informan sebagai sumber data yang dipilih secara purposive dan snowball sampling Sumber data 1 dalam penelitian ini memilih guru dan lembaga untuk mengetahui sejauh mana kendala proses pembelajaran daring online saat pandemi covid 19 dan sejauh mana inovasi guru dalam menyajikan media pembelajaran anak untuk terus dapat menyampaikan nilai-nilai dan pesan pembelajaran lembaga TK Aisyiah 07 Surabaya. Selanjutnya, akan ditindaklanjuti dengan menggali pendapat guru- guru di TK Aisyiah 07, Jl.Raya Kalibokor Surabaya

Teknik pengumpulan data 1 dilakukan untuk mengetahui potensi dan masalah dalam penelitian.Peneliti menggunakan metode kualitatif, sehingga teknik pengumpulan data yang digunakan adalah wawancara, dan dokumentasi

Dalam penelitian kualitatif, penyajian data bisa dilakukan dalam bentuk uraian singkat, bagan, hubungan antar kategori, flowchart, dan sejenisnya. Namun, yang paling sering digunakan untuk menyajikan data dalam penelitian kualitatif adalah dengan teks yang bersifat naratif. Menurut (Sugiyono, 2016) selain dengan teks naratif, dapat pula berupa grafik, matrik, network (jejaring kerja), dan chart.

Storytelling dapat dikembangkan untuk anak usia dini dalam meningkatkan kemampuan dan pengetahuan anak, hal ini efektif dilakukan sesuai dengan hasil penelitian (Ramdhani et al., 2019). Pada umunya pada pendidikan anak usia dini dapat mengembangkan kegiatan storytelling untuk menumbuhkan kebiasaan anak(Lestari et al., 2020).

\section{HASIL PENELITIAN DAN PEMBAHASAN Hasil Validasi Pengembangan Digital StoryTelling}

Hasil desain produk pengembangan digital storytelling untuk menumbuhkan kebiasaan anak minum air ini telah melampaui validasi oleh validator ahli dan praktisi untuk mengujikeefektifan dan kepraktisan produk.

Hal ini sejalan menurut pendapat Nieveen (2010:94) kualitas suatu produk pada penelitian pengembangan ditentukan oleh beberapa kriteria yaitu: validity (kesahihan), effectiveness (keefektivan),danpracticality (kepraktisan).

Berupa analisis deskriptif kuantitatif. Peneliti menganalisis data validasi dari tim ahli/ validator internal dan diolah dengan rumus berikut:

$$
\mathrm{P}(\%)=\frac{\begin{array}{c}
\text { Jumlah } \\
\text { skor total }
\end{array}}{\begin{array}{c}
\text { Skor } \\
\text { maximal }
\end{array}} \underset{\%}{\mathrm{X} 100}
$$

Untuk mengetahui kualitas setiap komponen, skor yang diperoleh diubah menjadi persentase dengan skala $0-100 \%$ dengan interval persentase.

Tabel 1 Kriteria Interpretasi Skor Penilaian Pengembangan Digital Story Telling Untuk Menumbuhkan Kebiasaan Anak Minum air

\begin{tabular}{cc}
\hline Skor & Keterangan \\
\hline $75,1 \%-100 \%$ & Sangat Berkualitas \\
\hline $50,1 \%-75 \%$ & Berkualitas \\
\hline $25,1 \%-50 \%$ & Kurang Berkualitas \\
\hline $0 \%-25 \%$ & Tidak Berkualitas \\
\hline
\end{tabular}

Berdasarkan kriteria tersebut diperoleh skor hasil validasi materi isi $75,71 \%$, validasi ahli story telling $82,14 \%$, validasi desain $72,85 \%$ Sehingga dapat 
disimpulkan berdasarkan kriteria interpretasi tersebut pengembangan digital storytelling untuk menumbuhkan kebiasaan anak minum air kategori sangat berkualitas.karena keterbatasan waktu penelitian sehingga saran dan revisi dapat disempurnakan pada penelitian selanjutnya.Pada Tahapan Ini berdasarkan analisis kebutuhan yang dilakukan melalui intrumen wawancara dengan kepala sekolah dan guru Taman Kanak-kanak Aisyiah 07 Surabaya dalam proses pembelajaran daring saat situasi pandemi covid 19, dimana anatara guru dan siswa tidak dapat melakukan aktivitas pembelajaran secara tatap muka. Di saat pandemi guru dituntut kreatif dan inovatif untuk tetap dapat menyajikan proses belajar daring online yang menarik minat bagi anak (Santrock, 2011).

Sehingga hasil analisis kebutuhan melalui intrumen wawancara, maka guru dan lembaga membutuhkan pengembangan media digital untuk dapat mengedukasi pembelajaran secara daring sehingga tetap dapat memberikan pesan-pesan moral yang menarik bagi anak, dalam hal ini pengembangan digital story telling untuk menumbuhkan kebiasaan anak minum air. Hal ini sesuai dengan pendapat (Mulyasa, 2011) bahwa untuk menyusun media harus memperhatikan kebutuhan guru dan lembaga dalam memenuhi kebutuhan belajar siswa ,perencanaan dan desain kebutuhan dalam hal ini ditunjukan dalam hasil lembar wawancara guru dan Kepala Sekolah.

\section{Desain dan Pengembangan Digital StoryTelling}

Pada tahap ini berdasarkan analisis kebutuhan peneliti mulai mendesain pengembangan produk digital story telling yang mempunyai beberapa elemen (Booth, 1994): a). Point of view atau sudut pandang Point of view merupakan sudut pandang dari penciptanya, sehingga perspektifnya tergantung dari pembawa cerita atau pengarangnya. Pengarang harus fokus terhadap apa yang akan diceritakan, dengan mempersiapkan segala macam materi yang dibuat semenarik mungkin; b). Dramatic question atau sebuah pertanyaan drama Pertanyaan akan terjawab pada akhir cerita, biasanya berupa kesimpulan dari keseluruhan cerita atau tujuan; c). Emotional content atau konten emosional. Konten dalam cerita biasanya menarik emosional atau persuasive; d). The gift of your voice atau pemberian suara. Pemberian suara merupakan cara bagaimana pembawa cerita ini dapat bernarasi dengan baik, sehingga audience dapat memahami apa yang akan disampaikan; e). The power of the soundtrack atau kekuatan musik pengiring. Unsur penunjang berupa alunan suara musik atau suara yang dapat mendukung suasana. Selain itu juga, pembawaan dari si pembicara juga harus menarik tidak hanya dari segi suara, tetapi juga gesture/ gaya tubuh, mimik, serta pembawaan lainnya. Story telling dapat menumbuhkan minat anak terhadap sesuatu(Haerudin, 2018).

\section{Implementasi (Penyebaran)}

Pada tahap ini dengan hasil rekomendasi dan hasil penilaian produk digital story telling yang sudah melampaui evaluasi / validasi internal yang diperoleh dari pendapat ahli dan praktisi, maka masuklah pada tahap penggunaan hasil produk pengembangan digital story telling pada skala yang lebih luas sebagai media pembelajaran daring online guru atau pendidik dalam sentuhan nilai-nilai menumbuhkan kebiasaan anak minum air.

Produk pengembangan digital story telling dikemas dalam bentuk kanal YouTobe. Karena di era digital seperti ini hadirlah kanal Youtube dengan berbagai referensi video dalam kategori yang banyak diminati oleh masyarakat.Kategori tersebut meliputi, komedi, film, edukasi, animasi, sport, music, game, traveling, review, news, dan tutorial. Dari kebanyakan kategori tersebut tentunya content creatoryang kreatif dan memiliki dan ide - ide out of the box,sehingga hasil pengembangan digital storytelling dapat didistribusikan kapada setiap guru atau lembaga pendidikan dengan mudah aksesnya, dan fleksibel penggunaanya pada zaman sekarang untuk skala yang lebih luas.

Hasil pengembangan digital story telling untuk menumbuhkan kebiasaan anak minum air dapat diakses melalui kanal youtube: Story Telling "Rekreasi Kekebun Wisata".

Air putih merupakan sumber terbaik untuk mencukupi kebutuhan cairan tubuh. Air paling alami tidak mengandung pewarna, pemanis dan perasa. Selama ini kita tak menyadari jika anakanak banyak yang kurang minat untuk terbiasa minum air putih.Sehingga sering terjadi kekurangan cairan yang berpengaruh pada pola kesehatan dan menggangu tumbuh kembang anak.Untuk kebutuhan air pada anak setiap hari tidak jauh berbeda dengan orang dewasa. Kebutuhan cairannya mencapai rata-rata anak yang telah berusia lebih dari satu tahun, maka sesuai dengan angka kecukupan gizi 2013 yang ditentukan Kementerian Kesehatan Republik Indonesia,yaitu: 1) Usia 1-3 tahun: membutuhkan cairan sebanyak 1150-1200 ml (4-5 gelas) per hari; 2) Usia 4-6 tahun:membutuhkan cairan sebanyak $1450-1500 \mathrm{ml}$ (6 gelas) perhari.

Anak perlu minum air lebih banyak, kekurangan minum air putih dapat menyebabkan dehidrasi yang akan memiliki dampak menurunkan kemampuan aktifitas fisik (Kleiner, 1999). Kekurangan air akan berdampak pada ketahanan fisik anak yang menurun, lebih mudah lelah, kelesuan dan 
penurunan fungsi kognitif otak anak (D'Anci, 2005). Dampak lain yang menganggu pada perkembangan anak adalah berkurangnya kemampuan konsentrasi anak atau kefokusan dengan menurunnya daya ingat (Benton dan Burgess, 2009).

Untuk itu menumbuhkan kebiasaan mengkonsumsi air putih pada anak sangat penting agar anak tidak terbiasa menyukai minuman bergula/berasa dan berkalori yang dapat meningkatkan resiko obesitas pada anak dan berakibat penyakit kronis dewasa kelak. Oleh sebab itu, minum air putih harus dibiasakan sejak usia dini. Perlunya membangun pemahaman konsep pada anak usia dini untuk menumbuhkan kebiasaan anak minum air. Diperlukan program dan metode pembelajaran yang mampu menarik minat, dan motifasi yang cukup mengedukasi anak sejak dini dan orang tua sebagai pendamping kehidupan sehari-hari anak dirumah.

\section{SIMPULAN}

Berdasarkan hasil penelitian dan proses pengembagangan digital storytelling untuk menumbuhkan kebiasaan anak minum air dapat disimpulkan bahwa pengembangan digital storytelling untuk menumbuhkan kebiasaan anak usia minum air memenuhi kelayakan dengan hasil validasi dari tiga validator ahli yang meliputi materi isi dengan skor 75,71\%, materi teknik storytelling skor $82,14 \%$,materi desain pengembangan digital storytelling skor 72,85\% dengan kategori sangat berkualitas, pengembangan digital storytelling untuk menumbuhkan kebiasaan anak minum air merupakan hasil pengembangan media pembelajaran yang dapat membantu daring online guru disaat pandemi untuk tetap dapat mengedukasi yang menarik minat anak dan meningkatkan motivasi wawasan anak dan orang tua akan pentingnya menumbuhkan kebiasaan minum air sejak dini, berdasarkan hasil validasi pengembangan digital storytelling untuk menumbuhkan kebiasaan anak minum air cukup praktis dan efektif diimplementasikan karena dikemas dalam bentuk kanal youtobe,sehingga mudah di akses dengan mudah saat ini.

\section{DAFTAR PUSTAKA}

Benton dan Burgess. (2009). The effects of drinking on attention. Procedia - Social and Behavioral Sciences.

Booth. (1994). Digital Story Telling in Kindegarten:An Alternative Tool in Children's Way of Expresion. MCSER Publishing, Rome-Italy, Vol.4.

Cahyati, N., \& Kusumah, R. (2020). Peran Orang Tua Dalam Menerapkan Pembelajaran Di Rumah Saat
Pandemi Covid 19. Jurnal Golden Age, Universitas Hamzanwadi, 04(1), 4-6.

D'Anci, B.-D. et al. (2005). The effects of drinking on attention. Procedia - Social and Behavioral Sciences.

Dewi, W. A. F. (2020). Dampak COVID-19 terhadap Implementasi Pembelajaran Daring di Sekolah Dasar. Edukatif : Jurnal Ilmu Pendidikan, 2(1), 55-61. https://doi.org/10.31004/edukatif.v2i1.89

Haerudin, D. A. . N. C. (2018). PENERAPAN METODE STORYTELLING BERBASIS CERITA RAKYAT DALAM MENANAMKAN NILAI-NILAI KARAKTER ANAK. Jurnal Pelita PAUD, 3(1), 1-9. https://doi.org/https://doi.org/10.33222/pelitapaud. v3i1.420

Kleiner. (1999). The effects of drinking on attention. Procedia - Social and Behavioral Sciences.

Lestari, D. P., Yufiarti, Y., \& Supena, A. (2020). Implementing Religious Characters of Early Children in the Pandemic Time of Covid 19. International Journal of Multicultural and Multireligious Understanding, 7(10), 348. https://doi.org/10.18415/ijmmu.v7i10.2062

Mulyasa. (2011). Pembentukan karakter disiplin anak usia dini melalui metode pembiasaan di TK Aisyiyah Bustanul Atfal 33 kota Malang. Jurnal Pendidikan Nonformal.V, ol.XIV No.

Penmendikbud. (2014). Standar Nasional Pendidikan Anak Usia Dini.

Permendikbud No. 137 Tahun 2014. (n.d.). Standar Pendidikan Nasional.

Piaget dan Kohlberg. (1969). Comparing The Effects Of The Story Telling Method And TheConventional Method On The Interest, Motivation AndAchievement Of Chinese Primary School Pupils. Procedia - Social and Behavioral Sciences.

Ramdhani, S., Yuliastri, N. A., Sari, S. D., \& Hasriah, S. (2019). Penanaman Nilai-Nilai Karakter melalui Kegiatan Storytelling dengan Menggunakan Cerita Rakyat Sasak pada Anak Usia Dini. Jurnal Obsesi : Jurnal Pendidikan Anak Usia Dini, 3(1), 153. https://doi.org/10.31004/obsesi.v3i1.108

Santrock, J. W. (2011). Life Span Development (13th ed.). The McGraw-Hill Companies.

Subadrah.M.N, Najeemah. M. Y, S. C. . (2014). Comparing The Effects Of The Story Telling Method And TheConventional Method On The Interest, Motivation AndAchievement Of Chinese Primary School Pupils. Social and Behavioral Sciences. 
Sugiyono. (2016). Metode Penelitian Kuantitatif, Kualitatif dan $R \& D$. PT Alfabet.

Sugiyono. (2017). Metode Penelitian Kuantitatif. Alfa beta.

Sutarna, N., Acesta, A., Cahyati, N., Giwangsa, S. F., \& Iskandar, D. (2022). Dampak Pembelajaran

Daring terhadap Siswa usia 5-8 tahun. 6(1), 288297. https://doi.org/10.31004/obsesi.v5i2.1265

Wiranata, R. S. (2019). Rz. Ricky Satria Wiranata. 2(20), 101-146. 